\title{
What are the Problem Representations and Assumptions About Gender Underlying Research on Gender in Physics and Physics Education? A Systematic Literature Review
}

\author{
Carolina de Barros Vidor ${ }^{\circledR}$ Brazil \\ Anna Danielsson ${ }^{\circledR}$ Sweden \\ Flavia Rezende ${ }^{(0)}$ Brazil \\ Fernanda Ostermann ${ }^{\circledR}$ Brazil
}

This work offers a systematic literature review of Brazilian and international research on gender in physics and physics education published over the last decade (2010-2019). We draw on a poststructuralist analytical approach to discuss assumptions about gender and forms of problematization of gender inequalities in physics, referred as problem representations, underlying one hundred and thirty studies. Results show that most studies $(76.9 \%)$ assume a binary gender model that restricts "gender" to sex-specific issues related to female individuals. The "problem" is represented as the low number of women pursuing careers related to physics. The implied solution is to attract girls to physics and retain female academics in their careers. Around $22.3 \%$ of studies assume that "gender" is a relational construct that constitutes power relations between individuals, who may or may not conform to hetero-cis-normative social expectations. The "problem" is represented as the reproduction of gender discourses and stereotypes within and about the cultures of physics and physics education. Only one study assume "gender" as one of several axes of a complex and dynamic power system that constrains knowledge production in physics, then representing the "problem" as a matter of how theories and practices are perpetuated in the field. We conclude that a call for more gender diversity in physics and physics education should not only address hetero-cisnormative conceptions of gender, but should also challenge strict and specific cultural, social and epistemological norms within the physics community.

Keywords: gender; physics education research; problem representations; poststructuralist analysis; systematic literature review.

\section{Introduction}

The body of research on gender in science has been growing during the last years, mainly motivated by a persistent low proportion of women in careers related to science and technology (S\&T): around $28.8 \%$ of world's researchers are women (UNESCO, 2017). In this context, gender inequalities in science education have become of major concern for scientists and science educators, since the overall lack of interest from young 
students in science and the fact that girls seem to be less engaged in school science than boys might impact directly on the underrepresentation of women in S\&T (Hussénius, 2014). Over the past few years in Brazil, there has been a flourishing of initiatives aiming to stimulate girls' engagement with scientific activities and thereby increase the number of girls choosing to pursue a future career related to S\&T. Main Brazilian universities have been developing educational projects focused on "girls in science", such as Federal University of Rio Grande do Sul (2020), Federal University of Rio de Janeiro (2020), University of Campinas (2020) and University of Brasília (2020).

Gender research in science education investigates causes of gender inequalities in science engagement and possible ways to overcome it, and it gives special attention to the impacts of gender upon teaching and learning of science. Nevertheless, gender perspectives in science education research are not restricted to analysis of science classroom dynamics, since social and cultural aspects of the scientific development also play a role on the development of science education. Considering that the field of science education has historically emerged from natural sciences, it is necessary to take on account that "scientists have had a strong influence or even controlled what science education should include and what is important" (Hussénius, 2014, p. 256). For the same reason, it is noticeable that, although scholars at the fields of gender studies and feminist studies have been problematizing the construct of gender and its impact on scientific development for decades, scholars at natural sciences and science education have only begun to give proper attention to the knowledge emerging from those fields (Hussénius, 2014; Traxler et al., 2016). As a result, different conceptions of gender are usually implicit in gender research in science education. Studies on this topic indicate that conceptions of gender are underdiscussed even in the disciplines of biology and health education, in where issues of gender identity, sexuality, and sexual reproduction are part of the disciplinary content (Marin, 2019; Pereira \& Monteiro, 2015). It, thus, becomes an essential task to make such implicit assumptions explicit in order to scrutinize possible outcomes of research addressing gender inequalities in science and science education (Sinnes \& Løken, 2014).

The overarching aim of this paper is to contribute to the development of gender research in science education through a critical analysis of studies addressing issues of gender inequalities in physics and physics education. To accomplish that, we have conducted a systematic literature review of Brazilian and international studies published over the last decade (2010-2019). We discuss assumptions about gender and forms of problematization of gender inequalities underlying these studies, also pointing out its possible effects for physics education and academic training in physics and related programs. Forms of problematization of gender inequalities and its effects within educational and scientific contexts related to physics are hereby called problem representations (Bacchi, 2009). 


\section{Analytical framework}

Over a decade ago, the American feminist and historian of science Londa Schiebinger (2007) proposed a framework for analyzing "theory and practice of creating equality for women in science" (p. 369). The framework has three distinct analytical levels, which depicts different yet complementary kinds of solutions to the same problem: getting more women into science. The first level of analysis, the participation of women in science, focus on historical and sociological perspectives on women's engagement in science, and address policies aimed at supporting women's career in scientific institutions. The second level of analysis, gender in the cultures of science, evaluate how scientific practices and values have been shaped mainly by men, excluding women. Policies at this level aim to transform academic cultures as means to mitigate the effects of gender bias on women. Finally, the third level of analysis, gender in the results of science, address the impact of gender on scientific content. Schiebinger discuss, for example, how federal government regulations developed in the 1990s worked to reduce gender bias in medical research by making it mandatory to include women in clinical trials. Through proposing this framework, Schiebinger argued that "gender" should be incorporated into all scientific disciplines as an important analytical category, since human knowledge "may change dramatically when women become full partners in knowledge production" (Schiebinger, 2007, p. 369). A relevant aspect of the framework was the premise that government and institutional policies were simply addressing a problem that already existed out there, that is, the underrepresentation of women (either as researchers or as research subjects) in science. Such a premise is challenged by the "What is the problem represented to be?" framework, which "makes the case that policies do not address problems that exist; rather, they produce 'problems' as particular sorts of problems" (Bacchi \& Goodwin, 2016, p. 16).

"What is the problem represented to be?" (WPR) is an analytical framework originally developed by the Canadian-Australian political scientist Carol Bacchi (2009) within the field of policy analysis as a tool to critically analyze government practices and policy proposals. Drawing from a poststructuralist perspective of discourse analysis based on the Foucauldian tradition, which focus on power relations in society as expressed through knowledge and practices, Bacchi argues that policy-making process do not simply solve social problems, but actually create "problems". Here, the term "problem" (purposely marked with ") acquires a specific meaning that refers to "what is seen as in need of fixing" (Bacchi, 2009, p. 32). In doing so, the WPR approach changes the focus of policy analysis from the common assumption of problem - a situation that is taken to exist as a real condition - to conceptualizations of "problems" - then called problematizations. Therefore "the focus is not on how people shape problematizations, but on how issues are problematized - constituted as 'problems' - within policies" (Bacchi \& Goodwin, 2016, p. 39). Forms of problematization and its effects within a specific context are referred as problem representations. The poststructuralist perspective on problem representations implies that problematization is understood as a contingent process, that 
is, a process situated within historical, social, institutional and epistemological contexts.

The WPR approach was developed as an analytical tool in order to facilitate the identification, reconstruction, and interrogation of problem representations, while also pointing the analyst to the contextual factors bringing the problem representations into question (Bacchi \& Goodwin, 2016). Its analytical strategy has been applied in comparative studies across a broad range of disciplines such as education, gender and feminist studies, social sciences, and health sciences. Regardless the discipline, the WPR approach foregrounds the premise that not only policies but also research practices have the power to shape realities. Consequently "it becomes important politically to contest the view that research produces disinterested, objective contributions to solving clearly observable societal problems" (Bacchi, 2012, p. 142). However, the statement that problem representations are created within research practices do not suggest that researchers necessarily intend to represent a certain "problem" in a certain way. We highlight that, given the poststructuralist framework, no intentionality is considered under the WPR approach. In this work, we use the framework proposed by Schiebinger (2007) as a starting point to categorize selected studies. In addition, we apply the WPR approach as means to identify and discuss assumptions about gender and implicit, nonintentional conceptualizations about the "problem" (problem representations) of gender inequalities in physics and physics education underlying such studies. The research question that directs this work is: What are the problem representations and assumptions about gender underlying research on gender in physics and physics education?

\section{Gender in physics and physics education: previous reviews}

The importance of research addressing "issues of gender" in physics and physics education has been highlighted by main peer-review journals in the fields. For example, the journal Physical Review Special Topics: Physics Education Research published the special issue Focused Collection on Gender in Physics in 2016. More recently, the American Journal of Physics published a resource letter that provides an overview of American reports, statistics, reviews, empirical studies and theoretical works addressing the underrepresentation of women in science, in general, and in physics, particularly (Blue, Traxler, \& Cochran, 2019). Nonetheless, researchers' interest on the "effects of gender" on the process of teaching and learning physics is certainly not new, as the first paper on this topic was published in 1992 (Traxler et al., 2016). Since then, the field evolved to answer more complex research problems, thus constituting "a rich tradition of interdisciplinary research that studies the entanglement of gender and physics from different perspectives" (Götschel, 2011, p. 66). We briefly summarize previous reviews of the research literature on gender in physics and physics education published over the last decade (2010-2019) as means to offer an overview of this research field ${ }^{1}$.

1 We have selected previous reviews on gender in physics and physics education according to criteria for data collection described in the methods section. No preview review of Brazilian studies was found. 
Madsen, McKagan and Sayre (2013) review the literature on the gender gap on concept inventories (standardized assessment instruments) in physics, that suggest that female students usually under-perform in comparison to male students. After evaluating the impact of factors that possibly influence such results, the authors conclude that "the gender gap is most likely due to the combination of many small factors rather than any one factor that can easily be modified" (p. 1). Lewis et al. (2016) review research findings that highlights how the need to feel a sense of belonging in academic physics acts to inhibit the participation of women while stimulating the participation of men. The authors suggest some strategies that could improve women's sense of belonging in physics, such as having contact with female role models and receiving social support outside the classroom. Kelly (2016) explores research-based evidence on the engagement and persistence of women in undergraduate physics, and exemplify socio-psychological strategies to support them. She suggests, for example, social feedback to improve women's physics self-concept and self-efficacy. Finally, Traxler et al. (2016) review previous research on gender differences in students' participation, performance, and attitudes toward physics. The authors point out that studies in the field of physics education research usually have "taken an uncritical look at sex and gender as binary categories", also highlighting that "when a gap is noted between men and women, it is generally framed either implicitly or explicitly as 'why can't women be more like men?"' (Traxler et al., 2016, p. 4). As an alternative to the binary model of gender, the authors suggest a poststructuralist conception of gender, based on the theory of gender performativity developed by the American philosopher Judith Butler (1990).

\section{Methods: Steps for conducting the systematic literature review}

Although providing valuable insights about the entanglement of gender and physics - from which it is evident that gender inequalities in physics and physics education are caused by complex factors - previous reviews on this topic have some relevant limitations. They are restricted to the analysis of international studies published in physics education and science education journals, besides providing limited explanation of criteria for data collection or data analysis. Through this systematic literature review, we complement and extend previous reviews by covering a broader range of journals (physics education, science education, history, philosophy and sociology of science, science communication, gender and feminist studies) and providing a comprehensive method for data collection and critical analysis of studies. Moreover, we include Brazilian studies, thus situating Brazilian research in relation to international research on gender in physics and physics education and highlighting the implications of the review for the Brazilian educational and scientific context.

The systematic literature review (SLR) is a secondary research method "used to map, find, critically evaluate, consolidate and aggregate the results of relevant primary studies on an issue or specific research topic, as well as to identify gaps to be filled" (Dresch et al., 2015, pp. 129-130). Thus it is indicated as a first action in extensive 
research projects and best suitable for focused topics. The systematic aspect of the review concerns the use of a clear and predefined method for gathering publications, making it then possible to easily reproduce or update the review. Although different scholars may rely on diverse methods for conducting a SLR, in this work we considered the following steps: choice of database, selection of journals, definition of search terms and time interval, pre-evaluation of titles and abstracts, and choice of papers according to inclusion/exclusion criteria for data collection; and reading of full texts, compilation and critical analysis of results for data analysis. The critical analysis is the most important step, as it enables the generation of new research results (Dresch et al., 2015).

\section{Data collection}

Journals were initially chosen from Coordinating Agency for Advanced Training of Graduate Personnel (CAPES) database according to Qualis classification ${ }^{2}$. As a first step, we selected all journals whose scope included science education, physics education, science communication and history, philosophy or sociology of science classified in strata $^{3}$ A1, A2, B1, B2, B3, B4 or B5 in the teaching evaluation area. We also included journals focused on gender and feminist studies classified in strata A1, A2, B1, B2, B3, $\mathrm{B} 4$ or $\mathrm{B} 5$ in the interdisciplinary evaluation area. As a second step, we included three other international journals focused on gender and feminist studies (which were not classified into Qualis system) for presenting relevant research intersecting the fields of natural sciences and science education: Gender and Education, Journal of Women and Minorities in Science and Engineering, and Sex Roles. Total number of selected journals is shown in Table 1.

Table 1. Total number of Brazilian and international journals included in this systematic literature review according to journal's scope and related search terms

\begin{tabular}{|c|c|c|c|}
\hline Journal's scope & $\begin{array}{l}\text { Brazilian } \\
\text { journals }\end{array}$ & $\begin{array}{l}\text { International } \\
\text { journals }\end{array}$ & Search terms \\
\hline Science education & 31 & 20 & \multirow{2}{*}{$\begin{array}{l}\text { physics AND gender, } \\
\text { physics AND girls, } \\
\text { physics AND women }\end{array}$} \\
\hline History, philosophy or sociology of science & 4 & 3 & \\
\hline Physics education & 4 & 8 & gender, women, girls \\
\hline Science communication & 11 & 4 & \multirow{2}{*}{ physics } \\
\hline Gender and feminist studies & 10 & 7 & \\
\hline Total & 60 & 42 & \\
\hline
\end{tabular}

Using the online search in each journal webpage, we looked for terms "women",

2 Qualis is a journal classification system created by CAPES aiming to assess the scientific production of Brazilian graduation programs. Classification process follows general and specific criteria according to each evaluation area. Detailed information is available at <https://sucupira.capes.gov.br/>. Access on 21 Nov. 2019.

3 For 2013-2016 quadrennial evaluation, journals were classified under quality indicator strata ranging from A1, the highest; $\mathrm{A} 2$; B1; B2; B3; B4; B5; to C, with weight equal to zero. 
"girls", "gender" and "physics" (depending on journal's scope) throughout all indexes (titles, abstracts and full text) of papers published during the last decade (20102019). A first screening of titles and abstracts was done to identify studies that were not relevant in relation to the scope of this SLR. In this stage, we excluded studies concerning: (i) sexuality or sexual education; (ii) biology or healthy sciences; (iii) mathematics education; (iv) "physics" as one of STEM (science, technology, engineering and mathematics) disciplines, whose focus was not specifically on physics. In addition, we excluded Brazilian studies in which the term "gênero" discourse genre and papers identified as news, letter, interview, editorial, book review, project report or teaching proposal. Finally, after full reading of papers, we excluded studies based on results of large-scale international surveys (such as Programm for International Student Assessment - PISA and The Relevance of Science Education - ROSE), studies conducted in informal learning environments and in non-academic research institutes. This way only studies explicitly addressing issues of gender in formal educational contexts (schools, colleges, universities and academic research laboratories) were included in this SLR. As such, selected studies investigated how gender impacts on physics education at all educational levels (from primary school to doctoral studies) and how it impacts upon the career development of professors, lectures, postdoctoral researchers and academic scientists working in a physics academic department. For the purpose of this work, studies concerning Brazilian educational and scientific system are referred as Brazilian studies, while studies concerning other countries are referred as international studies, regardless the publication journal. In sum, twenty-five Brazilian and one hundred and five international studies published between 2010 and 2019 were selected for further analysis.

\section{Data analysis}

Data analysis was based on a poststructuralist analytical framework (Bacchi, 2009, 2012; Bacchi \& Goodwin, 2016) and done empirically from full reading of papers. All information considered relevant was coded and used to categorize studies in three analytical categories, inspired by the framework proposed by Schiebinger (2007). This initial categorization was based on common assumptions about gender underlying studies in the same category. We assume the premise that studies implicitly or explicitly presented a particular proposal as a way to address gender inequalities in physics and physics education, thus producing particular problem representations of the issue. Then, by identifying common problem representations, we used this to categorize studies into subcategories. However, we emphasize that theoretical and methodological approaches adopted by studies in the same category/subcategory were not homogeneous. Detailed criteria for studies categorization and any discrepancy between studies in the same category/subcategory are explained in the results section.

4 The word "gênero" can be translated from Portuguese to English both as "gender" and as "genre". 


\section{Results: Representing the "problem"}

We identified problem representations and assumptions about gender underlying onehundred and thirty studies according to three analytical categories: (i) the participation of women in physics and physics education; (ii) gender in the cultures of physics and physics education; and (iii) gender in the knowledge production in physics. The first category was divided into four subcategories: historical perspectives; women's experiences; metrics of inequality; and gender differences. The second category, for instance, was divided into three subcategories: representations of science; gender dynamics; and identities. Categorization of studies is summarized in Table 2.

Table 2. Total number and relative percentage of studies included in this systematic literature review according to each analytical category and subcategory.

\begin{tabular}{lcccccccc}
\hline & $\begin{array}{c}\text { Brazilian } \\
\text { studies }\end{array}$ & $\mathbf{\%}^{\mathbf{a}}$ & $\mathbf{\%}^{\mathbf{b}}$ & $\begin{array}{c}\text { International } \\
\text { studies }\end{array}$ & $\mathbf{\%}^{\mathbf{c}}$ & $\mathbf{\%}^{\mathbf{b}}$ & Total & $\mathbf{\%}^{\mathbf{b}}$ \\
\hline First analytical category & 20 & 80.0 & 15.4 & 80 & 76.2 & 61.5 & 100 & 76.9 \\
\hline Historical perspectives & 9 & 36.0 & 6.9 & 3 & 2.9 & 2.3 & 12 & 9.2 \\
\hline Women's experiences & 5 & 20.0 & 3.8 & 23 & 21.9 & 17.7 & 28 & 21.5 \\
\hline Metrics of inequality & 6 & 24.0 & 4.6 & 0 & 0.0 & 0.0 & 6 & 4.6 \\
\hline Gender differences & 0 & 0.0 & 0.0 & 54 & 51.4 & 41.5 & 54 & 41.5 \\
\hline Second analytical category & 5 & 20.0 & 3.8 & 24 & 22.9 & 18.5 & 29 & 22.3 \\
\hline Representations of science & 3 & 12.0 & 2.3 & 3 & 2.9 & 2.3 & 6 & 4.6 \\
\hline Gender dynamics & 2 & 8.0 & 1.5 & 14 & 13.3 & 10.8 & 16 & 12.3 \\
\hline Identities & 0 & 0.0 & 0.0 & 7 & 6.7 & 5.4 & 7 & 5.4 \\
\hline Third analytical category & 0 & 0.0 & 0.0 & 1 & 1.0 & 0.8 & 1 & 0.8 \\
\hline Total & 25 & 100 & 19.2 & 105 & 100 & 80.8 & 130 & 100 \\
\hline a) Percentan
\end{tabular}

a) Percentage in relation to Brazilian studies only; b) Percentage in relation to all studies; and c) Percentage in relation to international studies only

As shown in Table 1, the majority (76.9\%) of studies were placed in the first analytical category, where most Brazilian studies (36\%) focused on historical perspectives and most international studies (51.4\%) investigated gender differences. The second analytical category accounted for $22.3 \%$ of all studies and the third analytical category accounted for less than $1 \%$.

\section{The participation of women in physics and physics education}

Studies in the first analytical category focus on the participation of women in physics and physics education. Here, the term "participation of women" assumes diverse meanings. It could refers to the contributions of female scientists to scientific development in physics and related areas, as portrayed by studies in the subcategory of historical perspectives; it could refer to girls' interest (or lack of interest) in learning school physics, or to women's individual trajectories in academic physics, as addressed by studies in 
the subcategory of women's experiences; it could refer to the under-representation of women in academic physics, such as depicted by studies in the subcategory of metrics of inequality; it could refer to differences between girls' and boys' learning outcomes in school physics, or to differences in career paths of women and men in academic physics, as addressed by studies in the subcategory of gender differences. Furthermore, in Brazilian studies, the term "participation of women" may be replaced by "feminine participation"5 (Feltrin et al., 2016; Guedes et al., 2015; B. S. Lima et al., 2015; Ramos \& Tedeschi, 2015; Teixeira \& Freitas, 2015). Thus, it becomes necessary to clarify that, despite of being used interchangeably, these terms convey different meanings:

A "woman" is a specific individual; "gender" denotes power relations between the sexes and refers to men as much as to women; "female" designates biological sex; "feminine" refers to idealized mannerisms and behaviors of women in a particular time and place which might also be adopted by men (Schiebinger, 1999, p. 8).

While putting "women", "girls" and "females" under the spotlight, studies in the first analytical category assume that "issues of gender" are reduced to "issues of women". It follows that "gender" is used here as a descriptive category:

Although gender in this usage asserts that relationships between the sexes are social, it says nothing about why these relationships are constructed as they are, how they work, or how they change. In its descriptive usage, then, gender is a concept associated with the study of things related to women (Scott, 1986, p. 1057).

The conceptualization of gender as a descriptive category also implies that "gender" is used as a substitutive word for "sex". Perhaps avoiding the use of the word "sex" is a way of preventing discussions about gender inequalities from being reduced to questions of biological, sexual (i.e., sex-specific) differences in which women are seen as different from men - that is, in which men are the point of reference. This is a reasonable interpretation, since much has been said about supposed "innate deficiencies" of women for analytical, mathematical, and scientific thinking. However, the fact that the distinction between "sex" as a set of biological characteristics and "gender" as a social construct is being blurred and not explicitly discussed may act to perpetuate gender bias against women precisely because sexism, discrimination against women based on sex, usually happens in a "veiled, subtle way, and therein lies, precisely, its strength and effectiveness" (Silva \& Ribeiro, 2014, p. 455). Thus, how to discuss "sexism" and mitigate its effects on women without discussing "sex"?

Overall, studies in the first analytical category assume that the "problem" (the situation in need of "fixing") is the low number of women pursuing careers related to physics, so the "solution" implies in attracting young women to physics and retaining female academics who are already there. However, this assumption holds an implicit

5 We understand that, in this case, the word "feminine" is replacing the word "female". This may happen because in the Brazilian culture the words "female" ("fêmea") and "male" ("macho") are commonly used to refer to biological sex of (non-human) animals. When used to refer to human beings, these words may assume depreciative connotations, as if individuals were demonstrating (non-rational) instinctive behavior. 
contradiction. On the one hand, girls and women are endowed with a powerful agency, as it is up to girls to choose (or have an ambition for) learning physics and it is up to women to choose (or persist) to continue pursuing their careers related to physics. On the other hand, girls and women are victims of an oppressive system, as girls do not have access to "proper physics education" and women do not have access to "proper working conditions" in academic and scientific contexts. Nonetheless, it is unclear to which girls and women these studies refer, which points to the question: are "all girls" and "all women" in disadvantage in physics and physics education? Following the same idea, if we assume that educational and scientific system is meant to benefit boys and men, does it imply that "all boys" and "all men" can successfully engage with physics? These questions are posed to challenge the implicit notion that "gender" could be in any way restricted to "sex", if "sex" is understood as a binary and opposing category that reduce people to "male" or "female".

\section{Historical perspectives}

Studies in the subcategory of historical perspectives represent the "problem" as a matter of low awareness of women's contribution to scientific advancement. It is assumed that gender bias against female scientists will be reduced if their contributions become visible; girls will feel inspired to pursue a scientific career if they know about successful female scientists. Therefore, studies in this subcategory depict life and work of outstanding women scientists as a strategy to praise their great - although not properly recognized - contributions to the development of physics and its subfields. Scientists pictured were: Chien Shiung Wu (Maia Filho \& Silva, 2019a, 2019b); Emmy Nöther (Areas et al., 2019; Patrão, 2015); Grace Hopper, Hedy Lamarr, Katharine Blodget and Mária Telkes (Incerti \& Casagrande, 2018); Gertrude Scharff-Goldhaber (Goldhaber, 2016); Henrietta Leavitt (Barros, 2018); Lise Meitner (I. P. C. de Lima, 2015); Margrete Heiberg (Reichenbach \& Dragowski, 2017); Marie Curie (Cordeiro \& Peduzzi, 2011); Marietta Blau (Sime, 2013) and Rosalyn Yalow (Minella, 2017).

Studies were developed either from a traditional or a critical historical perspective. The traditional historical perspective follows assumptions stated by the history of women in science movement. This movement emerged in the 1970s, when biographies of female scientists became a central point in debates about underrepresentation of women in science. It emerged as a reaction to the common statement that women were not "capable" to pursue scientific enterprise (Schiebinger, 1987). As it became broadly accepted that women could be as competent scientists as men, revisiting biographies of famous women in science became a way of arguing that female scientists were as valid historical subjects as male scientists. In this perspective, depicting the history of women in science is a task to be done for its own sake. Consequently, there is no need to question traditional methods and narratives of history in science - the only need to be met is to put women on an equal footing with men in the history of scientific development. In other words, studies developed from a traditional historical perspective (Areas et al., 2019; Barros, 
2018; Cordeiro \& Peduzzi, 2011; Goldhaber, 2016; Incerti \& Casagrande, 2018; Patrão, 2015) do not question traditional historiography of science, "according to which only mainstream science was worth pursuing as a research field” (Filgueiras, 2001, p. 709).

In contrast, studies developed from a critical historical perspective question the mainstream perspective on scientific knowledge production, challenging its androcentric and value-neutral premises. This perspective highlights the importance of understanding scientific practices of scientists in relation to political and sociocultural contexts in which such practices were developed. Among studies analyzed in this subcategory, half were developed from a critical historical perspective (I. P. C. de Lima, 2015; Maia Filho \& Silva, 2019a, 2019b; Minella, 2017; Reichenbach \& Dragowski, 2017; Sime, 2013). Furthermore, only studies based on a critical historical perspective presented theoretical frameworks. For example, Reichenbach and Dragowski (2017) discussed power struggles involved in creating the first institute of physics in Argentina from the theoretical perspective of cultural imperialism in science, as proposed by Pyeson (1985). Minella (2017) presented career paths of five female scientists until they were awarded the Nobel Prize while discussing possible political interferences in the process of nomination for the award. The author based her analysis on perspectives from feminist critique of science as discussed by feminist scholars such as Haraway (1995), Harding (1998), Fox-Keller (2006) and Schiebinger (1999).

It is noticeable that the majority (75\%) of papers in this subcategory were Brazilian studies. Curiously, however, no Brazilian scientists were pictured. The open question here is: where does Brazilian scientists fit in the history of science? These studies fulfill the important function of disseminating and discussing seminal contributions made by international female scientists. However, the absence of studies dedicated to female Brazilian researchers may imply that the development of physics and related areas in Brazil happened without contribution of women, or even that their contribution was not relevant - none of them are true. We could mention, for instance, Sonja Ashauer, Elisa Frota-Pessôa and Amélia Império Hamburguer, among other researchers (Saitovich et al., 2015). Further, it is of fundamental importance to critically analyze and discuss trajectories of female researchers in Brazilian academic and scientific community. As such, not only their contributions should be made visible, but it would also be important to understand the reasons behind the general invisibility of their lives and works.

\section{Women's experiences}

The main goal of studies in the subcategory of women's experiences is to scrutinize women's educational and professional trajectories in physics and related areas. Then the "problem" is represented as a matter of identifying factors that would lead women to science and factors that would contribute to retaining women in their academic and scientific careers. Although studies in the subcategory of historical perspectives also present life and work of female scientists, those women can be considered outstanding scientists, whose contributions were exceptional in their fields of work. Nonetheless, 
most of historical scientists lived decades ago, in a time when women's access to academic and scientific careers was certainly much more restricted than it is nowadays. Therefore, it is arguably necessary to investigate contemporary women's experiences in order to understand the factors influencing their careers. Some questions proposed by studies about women's experiences were "how do women fit into today's sciences?" 6 (Santos, 2016, p. 801) or "does the field attract the same types of women today as it has in the past?" (Sax et al., 2016).

Despite the fact that these studies provide information about girls and women in six different countries, their results were, in most aspects, very similar to each other. We summarized results around four main factors shaping women's experiences: motivation, adversities, persistence and retention. Among twenty-eight papers, only one presented a cross-cultural study, developed between Brazil, India and the United States (Foote \& Garg, 2015). One study was conducted in Australia (Abraham \& Barker, 2018); one in Estonia (Talves, 2016); one in Germany (Lucht, 2014); four in Brazil (B. S. Lima, 2011, 2013; Santos, 2016; Silva \& Ribeiro, 2014); and twenty in the United States (see references below).

Motivational factors include reasons that led female students to develop affinity for physics classes at school or to pursue an academic degree in physics. The literature suggests that both intrinsic and extrinsic motivation play a role on women's choices. Some common examples of intrinsic motivation (self-motivation) pointed out were: a primary interest for science; love for the subject, for learning new things or for "building stuff" (Martínez et al., 2019); and ambition for a career path in academia (Sax et al., 2016). The extrinsic motivation was described as being related to family influence; encouragement and recognition from teachers (Hazari et al., 2017; Hazari \& Cass, 2018); pleasant school science experiences (Dabney \& Tai, 2014; Wang et al., 2018); and inspiration from historical scientists (Foote \& Garg, 2015). One study investigated the impact of five extrinsic motivational factors on the interest of female student's for a career in physical sciences: (i) having a single-sex physics class; (ii) having a female physics teacher; (iii) having female scientist guest speakers in physics class; (iv) discussing the work of female scientists in physics class; and (v) discussing the underrepresentation of women in physics class (Hazari et al., 2013). Only the last factor showed positive effect, which was explored in a later study (Lock \& Hazari, 2016).

Adverse factors are barriers, obstacles or challenges faced by women during their studies and professional development. Many women expressed facing tensions between their private and professional lives, caused primarily by difficulties in reconciling academic demands with family obligations. Some situations reported were related to: maternity (B. S. Lima, 2011, 2013; Nehmeh \& Kelly, 2018; Santos, 2016; Silva \& Ribeiro, 2014); work-life balance; highly competitive professional environment; hostile workplace climate; and daily situations of gender discrimination, sexual harassment (Aycock et al., 2019) and microaggressions (Barthelemy et al., 2016, 2015). Besides that, women

6 Quotes from Brazilian studies have been translated to English from the original Portuguese by the first author. 
reported negative feelings of social isolation related to being the only (or one of the very few) women in the physics department. All mentioned aspects contribute to a feeling of incompetence among female scientists, endorsed by a strong belief in "unachievable criteria of success" (Talves, 2016, p. 163). According to American studies, adverse factors are aggravated for women of color (who self-identify as Black, Latina, American Indian or Asian American) because of their gender and race/ethnicity (Horna \& Richards, 2018).

Persistence factors depicts strategies adopted by women to cope with adverse factors and, consequently, persist in pursuing a career in physics (Dabney \& Tai, 2013; McCormick et al., 2014). Three studies focused on actions taken by women of color to overcome the double threat of gender and race/ethnicity, reporting similar results (Johnson et al., 2017; Ko et al., 2014; Rosa \& Mensah, 2016). As summarized by Ko et al. (2014), main actions included "seeking an environment that enabled success, circumventing unsupportive advisors, combating isolation using peer networks, consciously demonstrating abilities to counteract doubt, finding safe spaces for their whole selves, getting out to stay in STEM, remembering their passion for science, and engaging in activism" (p. 171).

Retention factors are related to institutional actions that can contribute to women's persistence and success. Studies suggest the promotion of: network opportunities among women, as for example, in a conference dedicated to undergraduate women in physics (Buck et al., 2014); collaborative studying and working environment; contact with female role models and mentors; family-friendly working place; information about career options and opportunities inside and outside academia. One study reported "a carefully planned intervention to increase the commitment of department chairs in the physical sciences to the hiring and career advancement of women" (Greene et al., 2011, p. 1).

\section{Metrics of inequality}

The subcategory of metrics of inequality comprises studies whose focus is to quantitatively investigate gender inequalities in physics and physics education through analyzing the proportion of women enrolled in academic programs and the granting of fellowships to female academics. The problem representation underlying these studies is the low awareness of women's underrepresentation and disadvantages in the academic and scientific scenario. In other words, it is still necessary "to prove just how disadvantaged women" (Schiebinger, 1999, p. 33) in physics and related fields are. Only Brazilian studies were placed in this subcategory, having in common the focus on statistical analysis of national databases or institutional databases from universities and scientific associations as primary research method. We note that, when analyzing data from government federal databases (such as the Brazilian National Council for Scientific and Technological Development - CNPq, CAPES and Lattes Platform), these studies focused on data concerning "physics and astronomy" as fields of knowledge?.

7 This implies that such data does not concern the granting of financial support to researchers in the fields of physics education or science education, who receive scholarships in the "teaching" field of knowledge. 
In sum, the overall conclusion is that the proportion of women in physics and related programs in Brazil decreases as career progression occurs, as well as women's access to financial support for educational or research purposes. Studies show that, at undergraduate level, women represent around $23 \%$ of students graduating in physics bachelor and teacher training programs offered by Federal University of Santa Catarina - UFSC (Menezes et al., 2018); 22.7\% of fellows of Science Without Borders Program in physics programs at Unicamp (Feltrin et al., 2016); and 33\% of all scientific initiation fellows in physics and astronomy programs (B. S. Lima et al., 2015). At graduate level, the rate of female students and fellows in master and doctoral programs is around $21 \%$ (Areas et al., 2019; B. S. Lima et al., 2015; Peres Menezes et al., 2018). Concerning faculty level, the proportion of female professors in undergraduate and graduate departments of physics is less than 14\% (Areas et al., 2019; Ramos \& Tedeschi, 2015; Teixeira \& Freitas, 2015). Moreover, less than a third of productivity research fellowships ${ }^{8}$ in physics and astronomy are awarded to women (Guedes et al., 2015; B. S. Lima et al., 2015).

These studies present extensive statistical analysis about the situation of women in Brazilian academia. However, the impact of such data when they are not accompanied by a critical analysis of the reasons that keep women from progressing in academic careers is likely to be limited. For instance, the majority (70\%) of papers in this subcategory did not articulate data analysis with a theoretical framework. In fact, what most of these studies offered was freely "some rather speculative assumptions about the numerical situation presented" (Menezes et al., 2018, p. 334). In addition, the intersection of gender, race and social class is yet to be analyzed. Schiebinger (1999) argues, for example, that the proportion of women in science should "equal their proportion in the larger population" (p. 9). Considering that Brazilian population is mostly composed of women (51.7\%) and black people $(53.9 \%)^{9}$, it is reasonable to argue that research on this topic should also address the underrepresentation of black women as much as of black men, if we are all to stand up for more "diversity in race and gender" (Ferrari et al., 2018, p. 90) in Brazilian academic and scientific community.

\section{Gender differences}

Studies in the subcategory of gender differences focus on assessing how personal characteristics and effects of education reform may differ between men and women. Most studies developed quantitative investigations (usually followed by a sophisticated statistical analysis) through the "disaggregation of data by gender", aiming to depict "gender patterns", "gender effects", "gender disparities" or "gender gap". Here, then, "gender" is just "another important variable to include in the analyses" (Hochberg, Kuhn, \& Müller, 2018, p. 390). This could explain the popularity of the gender differences approach among physics education research community, since quantitative methods are common in this field and can be easily recognized by an audience of physicists.

8 Academic researchers granted with productivity research fellowship are considered scientific elite in Brazil.

9 This category refers to self-declared black and brown people. Information retrieved from $<$ https://educa.ibge. gov.br/jovens >. Access on 12 Dec. 2019. 
In fact, this subcategory comprises the majority (41.5\%) of analyzed papers. Studies are summarized below according to common research focus ${ }^{10}$.

a) Technology-based learning: two studies evaluated effects of the use of technology on learning physics concepts. Results showed similar effects on male and female students considering the use of smartphones (Hochberg et al., 2018) and computers (Domelen, 2010).

b) Psychological processes: four studies investigated how learning physics might impact on psychological processes of students. Results showed that learning physics concepts caused higher levels of anxiety among female pre-service physics teachers (Caliskan, 2017; Sahin, 2014), and it was more related to depressive symptoms among female high-school students (Aggeliki et al., 2017). A psychological intervention in introductory physics class helped to improve the performance of female college students on physics tests (Angeles et al., 2010).

c) Career development: four studies evaluated gender disparities among academics in relation to their career intentions and experiences. Results showed that, in relation to their male colleagues, female academics: reported more often to accept constraints or abandon career goals because of childcare (Langfeldt \& Mischau, 2018); were more likely affected by the imposter syndrome, were less satisfied with advisors and reported more often that they had relocated work because of spouse or partner (Ivie et al., 2016). In relation to graduate students enrolled in physics education research programs in the United States, one study indicated that women represented more than half of students in this field and reported positive career experiences similar to those of male students (Barthelemy et al., 2015).

d) Conceptual learning and problem solving: six studies investigated gender differences in the conceptual learning and problem solving of physics topics. Studies showed no significant statistical difference between male and female performance in relation, for example, to solutions of calculus-based force problems (Gülçiçek, 2019) or to the learning of magnetism concepts (Li \& Singh, 2017). The teaching of Einsteinian concepts to middle school students showed to increase girls' scores in physics (Kaur et al., 2017).

e) Active learning methodologies: fourteen studies evaluated the effects of active learning methodologies (including interactive engagement, active-engagement, active learning or collaborative learning) aiming to close the gender gap in students' performance in physics. Effects of active learning were usually evaluated through the application of physics pre- and post-tests. Most studies showed that female students improved their performance, that is, they had achieved similar post-test results as their male colleagues (Cahill et al., 2014; Olaniyan \& Govender, 2018). Other studies reported that active learning did not result in reducing the gender gap (Day et al., 2016; Gok, 2014; Karim et al., 2018). Nonetheless, we highlight that these results need to be approached with caution. As some studies point out, statistical methods used to evaluate the gender gap

10 Fifty-four studies were analyzed in this subcategory. However, due to the limited space of this paper, we chose to cite only the most recent studies when more than four studies presented the same research focus. 
in physics may have a significant impact on the measured effect sizes (Brewe et al., 2010; Day et al., 2016).

f) Intentions, interests and beliefs: twenty-four studies investigated students' intentions to study physics, as well as their interests and subjective beliefs (self-concept and self-efficacy) towards learning physics content. Studies evaluating students' intentions showed that boys were more likely to study non-compulsory physics at high school or university (Caspi et al., 2019; Sheldrake et al., 2017). However, one study showed that female undergraduate students who have had intention to study physics while at high school were more likely than males to graduate with a physics degree (Rodriguez et al., 2016). In middle school, studies reported that boys were more interest in topics related to physical sciences while girls were more interested in biological sciences (Kaur et al., 2018; Toma \& Villagrá, 2019). However, other studies showed no gender differences in subject preference (Caspi et al., 2019; Dare \& Roehrig, 2016). Finally, in relation to subjective beliefs, studies showed that female students presented lower self-efficacy (Marshman et al., 2018; Nissen \& Shemwell, 2016) and lower self-concepts (Bøe et al., 2011) towards physics than male students.

Finally, we understand that Traxler et al. (2016) have already raised strong critiques of studies focused on "gender differences" in physics education research, which we endorse. Studies in the subcategory of gender differences explicitly reduce "gender" to an objective and binary measure, implying that students' multiple identity markers, skills, interests and capabilities are reduced to two categories: "male" and "female". Moreover, male performance is assumed to be the standard to be achieved by female students, thus disseminating a binary gender deficit model which suggests that female students are "deficient in characteristics necessary to succeed" in physics (Traxler et al., 2016, p. 1).

\section{Gender in the cultures of physics and physics education}

Studies in the second analytical category shift the focus from individual experiences to gendered cultural contexts, taking as starting point the recognition that "language, styles of interactions, modes of dress, hierarchies of values and practices, have been formed by their predominantly male practitioners" (Schiebinger, 2007, p. 371). This means breaking with the view of gender neutrality in the practices of physics and physics education, which turned "issues of gender" into "issues of women". It follows that taking gendered cultural contexts into account opens the possibility to see "gender" as an analytical category:

Those who worried that women's studies scholarship focused too narrowly and separately on women used the term "gender" to introduce a relational notion into our analytic vocabulary. According to this view, women and men were defined in terms of one another, and no understanding of either could be achieved by entirely separate study (Scott, 1986, p. 1054).

The straightforward implication of such statement is that the adoption of gender 
as an analytical category requires the analysis of social relations between women and men, instead of the description of their experiences apart from each other. Nonetheless, it is still necessary to take into account norms and social conventions that delimit the conditions in which some individuals are recognized as women while others are recognized as men. It is worth noting that Western society is based on hetero-cis-normative ${ }^{11}$ assumptions, and that such assumptions also permeate science and science education. As argued by Barton and Yang (2000), science and science education are constituted as a "culture of power" that must be embraced by those who wish to succeed as scientists or science students. Not by chance, those who succeed are "mostly white, upper and middle class, male and heterosexual" (Barton \& Yang, 2000, p. 873). Further, "it is hard to be anything but White, male, cisgender, straight, and able-bodied and be recognized as a physicist, and that is a shame" (Traxler \& Blue, 2020, p. 147). Taking this into account, we highlight that gender can no longer be understood as a "property of individuals", or as a fixed and binary category which refers only to "male" and "female", but as a complex construct. To be able to take gender as a truly relational category, we must assume that without power relations between subjects - cisgender as much as transgender ${ }^{12}$; heterosexual as much as homosexual - gender cannot exist (Butler, 1990, 2004).

Besides that, expanding Schiebinger's considerations, we assume that the "cultures of science" are mainly but not only constructed through academic practice, as it also comprehends practices developed in school science and, in a broader sense, the ones embedded in popular science culture (i.e., as portrayed by mass media, scifi books, movies, etc.). In our analysis, we assume a constructionist understanding of culture, which claims that "culture is concerned with the production and the exchange of meanings - the 'giving and taking of meaning' - between the members of a society or group" (Hall, 2013, p. xviii). According to this, we recognize that studies in the second analytical category are based on an implicit problem representation: the meanings produced within and about the cultures of physics and physics education contribute to the reproduction of gender discourses and stereotypes, which reinforce the assumption that physics is something suita ble for "men", but not for "women". We understand that stereotyping is the practice of producing meanings that reduce "people to a few, simple, essential characteristics, which are represented as fixed by nature" (Hall, 2013, p. 247). Studies are discussed in the subcategories of representations of science, gender dynamics and identities.

11 According to Worthen (2016, p. 31), "hetero-cis-normativity represents a hierarchical system of prejudice in which cisgender individuals are privileged above non-cisgender individuals but also, negativity, prejudice, and discrimination may be directed toward anyone perceived as noncisgender and/or nonheterosexual".

12 "Cisgender" means that one's gender identity matches with their sex assigned at birth. "Transgender" means that one's gender identity differs from their sex assigned at birth. 


\section{Representations of science}

Studies in the subcategory of representations of science analyze how practices of representation (Hall, 2013) impact on the construction of meanings about scientific activity and scientists. In other words, the assumption made here is that practices of representation shape ideas not only about how physics is done (or how it should be done), but also about who is able (or not) to do it. These ideas can be explicitly or implicitly represented through language, signs and concepts. And because language, signs and concepts may have a material dimension, these ideas can be represented in texts, pictures, etc. The implication of such materiality is obviously relevant for science education research: shared meanings within and about the cultures of science can be scrutinized through the exam of science textbooks, sci-fi books and films, pictures (photos and drawings) of scientists, and science communication in the mass media (for example, in newspapers and magazines). Such examination was conducted by six studies.

One study evaluated the effects of media representations on female high school students' perceptions of science. After watching news about science and the work of scientists, girls described science as an activity of experimentation and discovery held mostly by male geniuses, portrayed as eccentric scientists. The girls explicitly related such stereotypical image to their male physics teacher (Reznik et al., 2017). Similar results were found in the drawings of scientists made by pre-service physics teachers, who commonly portrayed stereotypical conceptions of scientists, similar to Albert Einstein (Souza \& Silva, 2016). One study evaluated photos of scientists (physicists, biologists and chemists) at their workplaces available on websites of academic and scientific institutions, showing that those photos corroborate stereotypical and gendered images of science (Christidou \& Kouvatas, 2013). Two studies analyzed images from high school physics textbooks, finding that women were sub-represented or mostly portrayed in domestic work (Rosa \& Silva, 2015) and "the images either explicitly show White males or implicitly invoke masculinity and/or maleness" (Namatende-Sakwa, 2019, p. 373). Finally, one study investigated the influence of science fiction on students' interest in pursuing an academic degree in physics, discussing "how the entanglement of physics education and science fiction draws on a particular subgenre of science fiction" (Hasse, 2015, p. 922). While male undergraduate physics students were strongly influenced by hard techno-fantasies, female students demonstrated appreciation for soft science fiction. Despite that, materials depicting soft science fiction were not available at the library of the investigated university.

In sum, studies in this subcategory converge to the conclusion that representations of science disseminate a gendered image of the scientific activity, which reinforce traditional assumptions about sex roles and contribute for the general stereotypical image of scientists and distorted visions about scientific work. 


\section{Gender dynamics}

Studies in the subcategory of gender dynamics evaluate how social constructions of gender impacts on the social positioning of women and men in relation to each other. In doing so, these studies focus on processes of gender stereotyping and construction of gender relations rather than "measuring" women's performance in comparison to men, which implies a significant change of perspective in relation to studies in the subcategory of gender differences.

Investigations about gender relations explored effects of gender socialization and power asymmetries between men and women on their discourses. Analysis of high school students' statements about their disciplinary and professional preferences indicated socialization patterns that were shaped in a different way by boys and girls due to social pressures (Lima Jr. et al., 2011). This finding contributes to challenge "the argument that choices are 'freely' made" (Ryan, 2012, p. 171) in regard to students preferences, that is, it indicates that students preferences are shaped also by social expectations, rather than only by individual interest. An analysis of discursive interactions between undergraduate physics students suggested that males tended to take the lead more often, while females needed to adopt certain strategies to make their points of view visible (Lima Jr. et al., 2010). However, an evaluation of interaction between undergraduate students during collaborative work showed that the activity "helped disrupt some typical gender dynamics in that men did not dominate group discussions" (Gunter et al., 2010, p. 1035). The recognition of a "gender gap in course grades between female and male students" (Andersson \& Johansson, 2016, p. 1) lead to an investigation of its causes, showing that the perceived difference in achievement was, in fact, a difference in study choice more related to the physics program structure than to students' gender.

Moreover, studies depicting gender stereotypes contribute to challenge the common assumption that "gender bias" is something inflicted by men against women, putting women in a passive and victimized position. We emphasize that gender norms are held by women as much as by men and affect all people (even though not in the same way). For example, one study conducted in China showed that similar beliefs in traditional gender roles were shared by both male and female physicists, thus contributing to "reinforce women's subordination in physics" (Di et al., 2016, p. 330). According to a Finnish study, not only female, but also male physicists face conflicts to achieve work-life balance, recognizing that they have neglected their families because of work (Sannino \& Vainio, 2015). In relation to perceived differences of self-concepts between

girls and boys, results of an investigation concluded that students with greater feelings of gender compatibility tended to demonstrate greater self-concept in physics, despite of their gender identity (Koul et al., 2016). This idea is supported by studies addressing effects of "stereotype threat" (ST), which "states that one underperforms when negative stereotypes about one's racial or gender group are activated" (Hirshfield, 2010, p. 14). An investigation about ST in high school physics class demonstrated that "simply being in a typical physics testing situation may be enough to inhibit female performance compared 
with males" (Marchand \& Taasoobshirazi, 2013, p. 3057). Besides that, based on the analysis of similar situations, studies showed that both male and female professors demonstrated bias against female physics post-doctoral candidates (Eaton et al., 2019). Besides that, both male and female students tended to rate more negatively female physics professors (Graves et al., 2017; Hofer, 2015; Potvin \& Hazari, 2016; Zander et al., 2014).

\section{Identities}

Studies in the subcategory of identities investigate how individuals negotiate their subject positions in relation to implicit norms of physics. Here, "identity" does not mean a fixed and stable set of characteristic that someone is or has, but rather it refers to a complex and contingent process of individual adaptation and resistance to social and cultural norms. This perspective is held by poststructuralist accounts on identity, like the theory of performativity of Butler (1990). Butler's theoretical development on gender performativity "has strong underpinnings and would help further refine the current efforts of many physics education researchers to support gender diversity in the classroom" (Traxler et al., 2016, p. 5). Building from such theoretical underpins, investigations conducted by the seven studies analyzed in this subcategory contribute to understand the entanglement between personal, social and cultural aspects of identity development through the practices of physics. This approach implies that "doing physics" means at the same time "doing gender" or, in a broader sense, "doing identity" (Danielsson, 2012; Gonsalves et al., 2016).

We understand that studies in this subcategory contribute in two important ways to further develop gender research in physics and physics education. First, they challenge the implicit assumption that "just being a man" is sufficient to succeed in physics. This is surely not the case, because "certain ways of becoming a physicist and doing physics is privileged in this process" (Johansson et al., 2018, p. 205). As explored by these studies, there are "various forms of masculinities that are produced and reproduced in physics laboratory settings" (Gonsalves et al., 2016, p. 2), so men must conform to the dominant masculinity norms of the setting in order to be part of it. In the case of a plasma physics lab, for example, there is an "emphasis on the machines, the muscles and the physical efforts" (Pettersson, 2018, p. 125) that clearly confront the stereotypical image of the purely intellectual work of a theoretical physicist. Second, women must negotiate aspects of their gender identities in order to belong to their fields of work. For instance, the enactment of a female masculinity (Danielsson, 2012) may be a an available strategy for women who prefer to act in ways perceived as more "masculine" to fit in working places where traditional expressions of femininity (like wearing heels and make up, for example) are discouraged, as it is usually the case of physics departments. However, this may create a conflict for women who prefer to express themselves in more "feminine" ways (Gonsalves, 2014). Therefore, we agree that to discuss such issues contribute to "challenge heteronormative understandings of all men as desiring to be masculine and 
all women desiring to be feminine" (Danielsson, 2012, p. 37).

Finally, studies in the subcategory of identities show that individuals must adapt to general social and cultural norms - which go far beyond just adapting to gender expectations - in order to be recognized as competent physicists or competent physics students. As highlighted by Traxler and Blue (2020, p. 179), "gender is never the whole story". Such norms comprehend demonstrating genuine curiosity and interest for physics content, while also expressing specific personality traits - exaggerated confidence, arrogance, intelligence, "nerdiness" - and a shared belief in a hierarchical status between theoretical physics and applied or experimental physics (Bremer \& Hughes, 2017; Johansson, 2018; Johansson et al., 2018). Complementing this statement about hierarchical status between subfields of physics, we mention that a study has reported that, in a physics teacher training program, "physics teachers" were taken to be in a lower status than "physicists", or even not to be considered "physicists" at all (Larsson, 2019).

\section{Gender in the knowledge production in physics}

Studies in the third analytical category investigate "how gender inequalities, built in the institutions of science, have influenced the knowledge issuing from those institutions" (Schiebinger, 2007, p. 372). Schiebinger (1999) explains and exemplifies how scientific contents and theories have been marked by gender, especially in those fields where the object of study is sexed - as it is the case for life sciences, social sciences and biomedical research. However, theories of physics may not be gendered, and it may be difficult to point out if theories would have been developed in a different way if they were proposed by women instead of men. This issue has received attention from researchers who acknowledge that, among investigations addressing gender inequalities in physics, "there is an inclination to distinguish sharply between issues of 'physics' and issues of 'physicists"' (Bug, 2003, p. 881). In other words, while it may be reasonable to discuss "gender" within the social and cultural context of physics and how physicists perpetuate gender bias, it is taken for granted that scientific practice (and its results) in physics will remain the same, regardless physicists' gender.

It follows that research on gender in the knowledge production in physics is still an underdeveloped research area (Götschel, 2011). As so, we identified only one study which fall into the third analytical category. This may be explained by the complexity of the topic, which touches upon epistemological issues, while still dealing with the same social and cultural issues previously discussed. We expected that studies in the third analytical category would question not only how gender, but in fact how any identity marker (such as race, ethnicity, age, religion, sexuality, disability, etc.), ideologies and beliefs "can become a silent organizer of scientific theories and practices, setting priorities and determining outcomes" (Schiebinger, 1999, p. 154). According to this perspective, "gender" is seen as just one axis of a complex and dynamic power system that constrains knowledge production in physics. The implicit problem representation here is a matter of how theories and practices are perpetuated in the field. 
The case raised by López-Corredoira (2014) may help to add new insights into the discussion about underrepresentation of women in careers related to physics. One common argument made in relation to increasing the number of women in science is that this would result "in more diversity in ideas and strategies to solve different types of problems" (Ferrari et al., 2018, p. 90). However, the assumption that "gender diversity" necessarily translates into "diversity of ideas" constitutes a controversial debate. For instance, Whitten (2012, p. 128) argues that "including some women and men of color in the scientific community will not effect significant change in science as long as these diverse people are educated to be just like the white men who are already there".

López-Corredoira (2014) discuss how non-standard cosmological models are prevented to compete with the standard model of the "Big Bang theory". The author reports that, when proposing the organization of a doctoral school in astrophysics, he was advised to include "the name of some women among the list of possible invited speakers for gender balance, and more orthodox cosmologists" (p. 93). While the feedback about increasing the number of female speakers might have been a very positive input, he follows on describing how the advisory board for the event was articulated in a way to keep the profile of invited cosmologists as homogeneous as possible. That is, main discussions should be kept around the "greatness" of the standard cosmological model - position referred as "orthodox cosmology". The author even mentions that he have never heard about any women working as a "heterodox cosmologist". In this case, the ambition to achieve gender balance in the event was clearly irrelevant in face of the underrepresentation of speakers aligned with competing scientific models of the universe. In regard of this debate, we consider that the double question "do we need a more diverse community of physicists in order to change theories and practices of physics, or do we need to change theories and practices of physics in order to have a more diverse community of physicists?" is a valuable one and need yet to be answered.

\section{Concluding remarks}

This paper presented a systematic literature review of twenty-five Brazilian and one hundred and five international studies addressing issues of gender inequalities in physics and physics education published over the last decade (2010-2019). Based on a poststructuralist analytical framework, studies were categorized into three analytical categories according to common problem representations and assumptions about gender underlying these studies. Our analysis showed that studies in the first analytical category, the participation of women in physics and physics education, restrict the conception of gender to sex-specific issues related to female individuals, thus reducing gender inequalities to "women's issues". In these studies, the "problem" is represented as the low number of women pursuing careers related to physics, so the "solution" implies in attracting girls to physics and retaining female academics in their careers. Studies in the second analytical category, gender in the cultures of physics and physics education, assume that gender is a relational construct which constitutes power relations between 
individuals, who may or may not conform to hetero-cis-normative social expectations. Here, the "problem" is represented as the reproduction of gender discourses and stereotypes within and about the cultures of physics and physics education. The only study in the third analytical category, gender in the knowledge production in physics, assume gender is one of several axes of a complex and dynamic power system that constrains knowledge production in physics, then representing the "problem" as a matter of how theories and practices are perpetuated in the field.

In sum, the field of research on gender in physics and physics education is based on implicit assumptions not only about "gender", but also about "gender diversity", thus bringing into question the intersection of multiple identity markers. Some studies analyzed in this paper address the intersection of gender and race through investigating personal experiences and academic paths of black women enrolled in physics programs, as in the subcategory of women's experiences. Other studies investigate the entanglement of gender identity and gender expression, thus challenging hetero-cis-normative assumptions of gender, as in the subcategory of identities. We have attempted to discuss conceptualizations of "gender" and "gender diversity" in greater detail throughout the analysis of studies presented in the second and third analytical categories. Such analysis point to the fact that individuals studying and practicing physics must conform to strict and specific cultural, social and epistemological norms underlying the physics community. Finally we propose that it is important for physics and physics education to make room for individuals who differ from the typical physicist or physics student (who is not only and in the first place male, but also White, cisgender, heterosexual, middle class, nerd, highly intelligent) in order to make physics truly "diverse".

\section{Acknowledgements}

This study was financed in part by the Coordenação de Aperfeiçoamento de Pessoal de Nível Superior - Brasil (CAPES) — Finance Code 001.

\section{References}

Abraham, J., \& Barker, K. (2018). Motivation and Engagement with Physics: A Comparative Study of Females in Single-Sex and Co-educational Classrooms. Research in Science Education, 1-16. https://doi.org/10.1007/s11165-018-9770-3

Aggeliki, A., Miltiades, K., Antigoni-Elisavet, R., Evangelia, P., \& Loizos, Z. (2017). Correlation of understanding of physics and psychological symptoms among high-school students in Greece. Physics Education, 52(5), 055004. https://doi.org/10.1088/13616552/aa76f3

Andersson, S., \& Johansson, A. (2016). Gender gap or program gap? Students' negotiations of study practice in a course in electromagnetism. Physical Review Physics Education Research, 12(2), 020112. https://doi.org/10.1103/PhysRevPhysEducRes.12.020112 
Angeles, L., Mitsuhashi, F., Nasu, M., Suzuki, Y., Adolfssen, J. S., Bryant, H. N., ... Tomas, R. (2010). Reducing the gender achievement gap in college science: a classroom study of values affirmation. Science, 330(6008), 1234-1237. https://doi.org/10.1126/ science. 1195996

Areas, R., Barbosa, M. C., \& Santana, A. E. (2019). Teorema de Emmy Nöther, 100 anos: Alegoria da misoginia em ciência [Emmy Nöther's Theorem, 100 years: Allegory of the misoginy in science]. Revista Brasileira de Ensino de Física, 41(4), e20190017. https:// doi.org/10.1590/1806-9126-RBEF-2019-0017

Aycock, L. M., Hazari, Z., Brewe, E., Clancy, K. B. H., Hodapp, T., \& Goertzen, R. M. (2019). Sexual harassment reported by undergraduate female physicists. Physical Review Physics Education Research, 15, 010121. https://doi.org/10.1103/ PhysRevPhysEducRes.15.010121

Bacchi, C. (2009). Analysing policy: What's the problem represented to be? Pearson.

Bacchi, C. (2012). Strategic interventions and ontological politics: research as political practice. In A. Bletsas, \& C. Beasley (Eds.), Engaging with Carol Bacchi: Strategic Interventions and Exchanges (pp. 141-156). University of Adelaide Press.

Bacchi, C., \& Goodwin, S. (2016). Poststructural Policy Analysis: A guide to practice. Palgrave Macmillan US.

Barros, M. C. de. (2018). As mulheres do Harvard College Observatory: Henrietta Swan Leavitt - a mulher que descobriu como medir a distância da galáxias [Harvard College Observatory Women: Henrietta Swan Leavitt - the woman who discovered how to measure the distance of galaxies]. História Da Ciência e Ensino: Construindo Interfaces, 18(especial), 12-21. https://doi.org/10.23925/2178-2911.2018v18i1p12-21

Barthelemy, R., McCormick, M., \& Henderson, C. (2015). Barriers Beyond Equity: An Exploratory Study of Women Graduate Students' Career Pathways in Astronomy. International Journal of Gender, Science and Technology, 7(1), 57-73.

Barthelemy, R., McCormick, M., \& Henderson, C. (2016). Gender discrimination in physics and astronomy: Graduate student experiences of sexism and gender microaggressions. Physical Review Physics Education Research, 12(2), 020119. https:// doi.org/10.1103/PhysRevPhysEducRes.12.020119

Barthelemy, R., Van Dusen, B., \& Henderson, C. (2015). Physics education research: A research subfield of physics with gender parity. Physical Review Special Topics - Physics Education Research, 11(2), 020107. https://doi.org/10.1103/PhysRevSTPER.11.020107

Barton, A. C., \& Yang, K. (2000). The culture of power and science education: Learning from Miguel. Journal of Research in Science Teaching, 37(8), 871-889. https://doi. org/10.1002/1098-2736(200010)37:8<871::AID-TEA7>3.0.CO;2-9 
Blue, J., Traxler, A., \& Cochran, G. (2019). Resource Letter: GP-1: Gender and Physics. American Journal of Physics, 87(8), 616-626. https://doi.org/10.1119/1.5114628

Bøe, M. V., Henriksen, E. K., Lyons, T., \& Schreiner, C. (2011). Participation in science and technology: Young people's achievement-related choices in late-modern societies. Studies in Science Education, 47(1), 37-72. https://doi.org/10.1080/03057267.2011.5496 21

Bremer, M., \& Hughes, R. M. (2017). How novices perceive the culture of physics. Journal of Women and Minorities in Science and Engineering, 23(2), 169-192. https:// doi.org/10.1615/JWomenMinorScienEng.2017016953

Brewe, E., Sawtelle, V., Kramer, L. H., O’Brien, G. E., Rodriguez, I., \& Pamelá, P. (2010). Toward equity through participation in Modeling Instruction in introductory university physics. Physical Review Special Topics - Physics Education Research, 6(1), 010106. https://doi.org/10.1103/PhysRevSTPER.6.010106

Buck, G. A., Mills, M., Wang, J., \& Yin, X. (2014). Evaluating and exploring a professional conference for undergraduate women in physics. Journal of Women and Minorities in Science and Engineering, 20(4), 359-377. https://doi.org/10.1615/ JWomenMinorScienEng.2014008011

Bug, A. (2003). Has Feminism Changed Physics? Signs: Journal of Women in Culture and Society, 28(3), 881-899. https://doi.org/10.1086/345323

Butler, J. (1990). Gender trouble: Feminism and the subversion of identity. (L. J. Nicholson, Ed.). Routledge.

Butler, J. (2004). Undoing gender. Routledge.

Cahill, M. J., Hynes, K. M., Trousil, R., Brooks, L. A., McDaniel, M. A., Repice, M., ... Frey, R. F. (2014). Multiyear, multi-instructor evaluation of a large-class interactiveengagement curriculum. Physical Review Special Topics - Physics Education Research, 10(2), 020101. https://doi.org/10.1103/PhysRevSTPER.10.020101

Caliskan, S. (2017). Physics Anxiety of Pre-Service Teachers And Their Self-Efficacy Beliefs: Differences According to Gender and Physics Achievement. Journal of Baltic Science Education, 16(5), 678-693.

Caspi, A., Gorsky, P., Nitzani-Hendel, R., Zacharia, Z., Rosenfeld, S., Berman, S., \& Shildhouse, B. (2019). Ninth-grade students' perceptions of the factors that led them to major in high school science, technology, engineering, and mathematics disciplines. Science Education, 1-30. https://doi.org/10.1002/sce.21524

Christidou, V., \& Kouvatas, A. (2013). Visual self-images of scientists and science in Greece. Public Understanding of Science, 22(1), 91-109. https://doi. org/10.1177/0963662510397118 
Cordeiro, M. D., \& Peduzzi, L. O. D. Q. (2011). As Conferências Nobel de Marie e Pierre Curie: a gênese da radioatividade no ensino [Marie and Pierre Curie's Nobel Lectures: the genesis of radioactivity in class]. Caderno Brasileiro de Ensino de Física, 27(3), 473514. https://doi.org/10.5007/2175-7941.2010v27n3p473

Dabney, K. P., \& Tai, R. H. (2013). Female physicist doctoral experiences. Physical Review Special Topics - Physics Education Research, 9(1), 010115. https://doi.org/10.1103/ PhysRevSTPER.9.010115

Dabney, K.P., \& Tai, R. H. (2014). Comparative analysis of female physicists in the physical sciences: Motivation and background variables. Physical Review Special Topics - Physics Education Research, 10(1), 010104. https://doi.org/10.1103/PhysRevSTPER.10.010104

Danielsson, A. T. (2012). Exploring woman university physics students "doing gender" and "doing physics." Gender and Education, 24(1), 25-39. https://doi.org/10.1080/0954 0253.2011.565040

Dare, E. A., \& Roehrig, G. H. (2016). "If I had to do it, then I would": Understanding early middle school students' perceptions of physics and physics-related careers by gender. Physical Review Physics Education Research, 12(2), 020117. https://doi.org/10.1103/ PhysRevPhysEducRes.12.020117

Day, J., Stang, J. B., Holmes, N. G., Kumar, D., \& Bonn, D. A. (2016). Gender gaps and gendered action in a first-year physics laboratory. Physical Review Physics Education Research, 12(2), 020104. https://doi.org/10.1103/PhysRevPhysEducRes.12.020104

Di, D., Ecklund, E. H., \& Lewis, S. W. (2016). Women's underrepresentation in academic physics in the people's Republic of China. Journal of Women and Minorities in Science and Engineering, 22(4), 329-348. https://doi.org/10.1615/ JWomenMinorScienEng.2016015719

Domelen, D. Van. (2010). Gender Effects of Computer Use in a Conceptual Physics Lab Course. The Physics Teacher, 48, 534-536. https://doi.org/10.1119/1.3502507

Dresch, A., Lacerda, D. P., \& Antunes Jr., J. A. V. (2015). Design science research: A method for science and technology advancement. Springer.

Eaton, A. A., Saunders, J. F., Jacobson, R. K., \& West, K. (2019). How Gender and Race Stereotypes Impact the Advancement of Scholars in STEM: Professors' Biased Evaluations of Physics and Biology Post-Doctoral Candidates. Sex Roles, 1-15. https:// doi.org/10.1007/s11199-019-01052-w

Feltrin, R. B., Costa, J. O. P. da, \& Velho, L. (2016). Mulheres sem fronteiras? Uma análise da participação das mulheres no Programa Ciência sem Fronteiras da Unicamp: motivações, desafios e impactos na trajetória profissional [Women without borders? A study on the participation of women in Unicamp's 'Science Without Borders' Programme: Motivations, challenges and impacts on professional trajectory]. Cadernos Pagu, 48, e164804. https://doi.org/10.1590/18094449201600480004 
Ferrari, N. C., Martell, R., Okido, D. H., Romazini, G., Barbosa, M. C., \& Brito, C. (2018). Geographic and gender diversity in the Brazilian Academy of Sciences. Anais Da Academia Brasileira de Ciências, 90(2 suppl 1), 2543-2552. https://doi.org/10.1590/00013765201820170107

Filgueiras, C. A. L. (2001). History of science and its object of study: Confrontations amongst peripheral science, mainstream science and marginal science. Química Nova, 24(5), 709-712.

Foote, K., \& Garg, R. (2015). A cross-cultural survey of female undergraduates' aspirations for scientific study and careers. Revista Brasileira de Ensino de Física, 37(1), 1309. https://doi.org/10.1590/S1806-11173711670

Fox-Keller, E. (2006). Qual foi o impacto do feminismo na ciência? [What impact, if any, has feminism had on science?]. Cadernos Pagu, 27, 13-34. https://doi.org/10.1590/ S0104-83332006000200003

Gok, T. (2014). Peer Instruction in the physics clasroom: Effects of gender difference on performance, conceptual learning, and problem solving. Journal of Baltic Science Education, 13(6), 776-788.

Goldhaber, M. H. (2016). Gertrude Scharff-Goldhaber, 1911-1998: Nuclear Physicist Against the Odds. Physics in Perspective, 18(2), 182-208. https://doi.org/10.1007/ s00016-016-0181-4

Gonsalves, A. J. (2014). "Physics and the girly girl-there is a contradiction somewhere": Doctoral students' positioning around discourses of gender and competence in physics. Cultural Studies of Science Education, 9(2), 503-521. https://doi.org/10.1007/s11422012-9447-6

Gonsalves, A. J., Danielsson, A. T., \& Pettersson, H. (2016). Masculinities and experimental practices in physics: The view from three case studies. Physical Review Physics Education Research, 12(2), 1-15. https://doi.org/10.1103/PhysRevPhysEducRes.12.020120

Götschel, H. (2011). The entanglement of gender and physics: Human actors, work place cultures, and knowledge production. Science Studies, 24(1), 66-80.

Graves, A. L., Hoshino-Browne, E., \& Lui, K. P. H. (2017). Swimming against the tide: Gender bias in the physics classrom. Journal of Women and Minorities in Science and Engineering, 23(1), 15-36. https://doi.org/10.1615/JWomenMinorScienEng.2017013584

Greene, J., Lewis, P., Richmond, G., \& Stockard, J. (2011). Addressing gender equity in the physical sciences: Replications of a workshop designed to change the views of department chairs. Journal of Women and Minorities in Science and Engineering, 17(2), 97-109. https://doi.org/10.1615/JWomenMinorScienEng.2011002835 
Guedes, M. de C., Azevedo, N., \& Ferreira, L. O. (2015). A produtividade científica tem sexo? Um estudo sobre bolsistas de produtividade do CNPq [Is Scientific Production Sexed? A Study of Recipients of CNPq Productivity Scholarships]. Cadernos Pagu, 45, 367-399. https://doi.org/10.1590/18094449201500450367

Gülçiçek, Ç. (2019). Analysis of physics students' problem solutions: Calculating the work done by a three-dimensional conservative force field. European Journal of Physics, 40(2), 025702. https://doi.org/10.1088/1361-6404/aaf661

Gunter, R., Spiczak, G., \& Madsen, J. (2010). Cosmic collaboration in an undergraduate astrophysics laboratory. American Journal of Physics, 78(10), 1035-1047. https://doi. org $/ 10.1119 / 1.3453247$

Hall, S. (2013). Representation: Cultural Representations and Signifying Practices (Culture, Media and Identities). (S. Hall, J. Evans, \& S. Nixon, Eds.) (2nd ed.). The Open University.

Haraway, D. (1995). Saberes localizados: A questão da ciência para o feminismo e o privilégio da perspectiva parcial [Situated knowledges: The science question in feminism and the privilege of partial perspective]. Cadernos Pagu, 5, 7-41.

Harding, S. (1998). Is science multicultural? Postcolonialisms, feminisms, and epistemologies. Indiana University Press.

Hasse, C. (2015). The material co-construction of hard science fiction and physics. Cultural Studies of Science Education, 10(4), 921-940. https://doi.org/10.1007/s11422013-9547-y

Hazari, Z., Brewe, E., Goertzen, R. M., \& Hodapp, T. (2017). The Importance of High School Physics Teachers for Female Students' Physics Identity and Persistence. The Physics Teacher, 55(2), 96-99. https://doi.org/10.1119/1.4974122

Hazari, Z., \& Cass, C. (2018). Towards Meaningful Physics Recognition: What does this recognition actually look like? The Physics Teacher, 56(7), 442-446. https://doi. org $/ 10.1119 / 1.5055325$

Hazari, Z., Potvin, G., Lock, R. M., Lung, F., Sonnert, G., \& Sadler, P. M. (2013). Factors that affect the physical science career interest of female students: Testing five common hypotheses. Physical Review Special Topics - Physics Education Research, 9(2), 1-8. https://doi.org/10.1103/PhysRevSTPER.9.020115

Hirshfield, L. E. (2010). "She Won't Make Me Feel Dumb": Identity Threat in a MaleDominated Discipline. International Journal of Gender, Science and Technology, 2(1), 6-24.

Hochberg, K., Kuhn, J., \& Müller, A. (2018). Using Smartphones as Experimental Tools_ Effects on Interest, Curiosity, and Learning in Physics Education. Journal of Science Education and Technology, 27(5), 385-403. https://doi.org/10.1007/s10956-018-9731-7 
Hofer, S. I. (2015). Studying Gender Bias in Physics Grading: The role of teaching experience and country. International Journal of Science Education, 37, 2879-2905. https://doi.org/10.1080/09500693.2015.1114190

Horna, C., \& Richards, A. J. (2018). Investigating Physics Self-Belief of Female African-American Students. The Physics Teacher, 56(7), 448-451. https://doi. org/10.1119/1.5055326

Hussénius, A. (2014). Science education for all, some or just a few? Feminist and gender perspectives on science education: A special issue. Cultural Studies of Science Education, 9(2), 255-262. https://doi.org/10.1007/s11422-013-9561-0

Incerti, T. G., \& Casagrande, L. S. (2018). Elas fizeram parte da história da ciência e da tecnologia e são inventoras sim! [They have made (and are) part of the history of science and technology and are inventors!]. Cadernos de Gênero e Tecnologia, 11(37), 5-26. https://doi.org/10.3895/cgt.v11n37.7271

Ivie, R., White, S., \& Chu, R. Y. (2016). Women's and men's career choices in astronomy and astrophysics. Physical Review Physics Education Research, 12(2), 020109. https://doi. org/10.1103/PhysRevPhysEducRes.12.020109

Johansson, A. (2018). Negotiating Intelligence, Nerdiness, and Status in Physics Master's studies. Research in Science Education, 1-22. https://doi.org/10.1007/s11165-018-97868

Johansson, A., Andersson, S., Salminen-Karlsson, M., \& Elmgren, M. (2018). "Shut up and calculate": the available discursive positions in quantum physics courses. Cultural Studies of Science Education, 13, 205-226. https://doi.org/10.1007/s11422-016-9742-8

Johnson, A., Ong, M., Ko, L. T., Smith, J., \& Hodari, A. (2017). Common Challenges Faced by Women of Color in Physics, and Actions Faculty Can Take to Minimize Those Challenges. The Physics Teacher, 55(6), 356-360. https://doi.org/10.1119/1.4999731

Karim, N. I., Maries, A., \& Singh, C. (2018). Do evidence-based active-engagement courses reduce the gender gap in introductory physics? European Journal of Physics, 39(2), 025701. https://doi.org/10.1088/1361-6404/aa9689

Kaur, T., Blair, D., Moschilla, J., Stannard, W., \& Zadnik, M. (2017). Teaching Einsteinian physics at schools: part 3, review of research outcomes. Physics Education, 52(6), 065014. https://doi.org/10.1088/1361-6552/aa83dd

Kaur, T., Blair, D., Stannard, W., Treagust, D., Venville, G., Zadnik, M., ... Perks, D. (2018). Determining the Intelligibility of Einsteinian Concepts with Middle School Students. Research in Science Education, 1-28. https://doi.org/10.1007/s11165-0189791-y Determining

Kelly, A. M. (2016). Social cognitive perspective of gender disparities in undergraduate physics. Physical Review Physics Education Research, 12(2), 020116. https://doi. org/10.1103/PhysRevPhysEducRes.12.020116 
Ko, L. T., Kachchaf, R. R., Hodari, A. K., \& Ong, M. (2014). Agency of women of color in physics and astronomy: strategies for persistence and success. Journal of Women and Minorities in Science and Engineering, 20(2), 171-195. https://doi.org/10.1615/ JWomenMinorScienEng.2014008198

Koul, R., Lerdpornkulrat, T., \& Poondej, C. (2016). Gender compatibility, math-gender stereotypes, and self-concepts in math and physics. Physical Review Physics Education Research, 12(2), 020115. https://doi.org/10.1103/PhysRevPhysEducRes.12.020115

Langfeldt, B., \& Mischau, A. (2018). Change and Persistence of Gender Disparities in Academic Careers of Mathematicians and Physicists in Germany. International Journal of Gender, Science and Technology, 10(1), 147-170.

Larsson, J. (2019). Becoming a physics teacher: disciplinary discourses and the development of professional identity. Licenciate dissertation. Department of Physics and Astronomy, Physics Education Research, Uppsala University. Uppsala, Sweden.

Lewis, K. L., Stout, J. G., Pollock, S. J., Finkelstein, N. D., \& Ito, T. A. (2016). Fitting in or opting out: A review of key social-psychological factors influencing a sense of belonging for women in physics. Physical Review Physics Education Research, 12(2), 020110. https:// doi.org/10.1103/PhysRevPhysEducRes.12.020110

Li, J., \& Singh, C. (2017). Developing and validating a conceptual survey to assess introductory physics students' understanding of magnetism. European Journal of Physics, 38(2), 025702. https://doi.org/10.1088/1361-6404/38/2/025702

Lima, B. S. (2011). Quando o amor amarra: reflexões sobre as relações afetivas e a carreira científica [When love ties in: reflections on affective relationships and the scientific career]. Revista Gênero, 12(1), 9-21. https://doi.org/10.22409/rg.v12i1

Lima, B. S. (2013). O labirinto de cristal: as trajetórias das cientistas na Física [The glass labyrinth: the women scientific's trajectories in Physics]. Revista Estudos Feministas, 21(3), 883-903. https://doi.org/10.1590/S0104-026X2013000300007

Lima, B. S., Braga, M. L. de S., \& Tavares, I. (2015). Participação das mulheres nas ciências e tecnologias: entre espaços ocupados e lacunas [Participation of women in science and technology: between occupied spaces and gaps]. Revista Gênero, 16(1), 11-31. https:// doi.org/10.22409/rg.v16i1.743

Lima, I. P. C. de. (2015). Lise Meitner e a fissão nuclear: uma visão não eurocêntrica da ciência [Lise Meitner and nuclear fission: a non-Eurocentric view of science]. Revista Gênero, 16(1), 51-65. https://doi.org/10.22409/rg.v16i1

Lima Jr, P., Ostermann, F., \& Rezende, F. (2010). Liderança e gênero em um debate acadêmico entre graduandos em Física [Leadership and Gender in an academic debate amid Physics Undergraduate Students]. Revista Brasileira de Pesquisa Em Educação Em Ciências, 10(1), 1-16. 
Lima Jr, P., Rezende, F., \& Ostermann, F. (2011). Diferenças de gênero nas preferências disciplinares e profissionais de estudantes de nível médio: Relações com educação em ciências [Gender differences in high school student's preferences on subject matters and professional choices: Connections with science education]. Revista Ensaio: Pesquisa e Educação Em Ciências, 13(2), 119-134.

Lock, R. M., \& Hazari, Z. (2016). Discussing underrepresentation as a means to facilitating female students' physics identity development. Physical Review Physics Education Research, 12(2), 020101. https://doi.org/10.1103/PhysRevPhysEducRes.12.020101

López-Corredoira, M. (2014). Non-standard models and the sociology of cosmology. Studies in History and Philosophy of Science Part B: Studies in History and Philosophy of Modern Physics, 46, 86-96. https://doi.org/10.1016/j.shpsb.2013.11.005

Lucht, P. (2014). De-Gendering STEM - Lessons Learned from an Ethnographic Case Study of a Physics Laboratory. International Journal of Gender, Science and Technology, $8(1), 67-81$.

Madsen, A., McKagan, S. B., \& Sayre, E. C. (2013). Gender gap on concept inventories in physics: What is consistent, what is inconsistent, and what factors influence the gap? Physical Review Special Topics - Physics Education Research, 9(2), 020121. https://doi. org/10.1103/PhysRevSTPER.9.020121

Maia Filho, A. M., \& Silva, I. L. (2019a). A trajetória de Chien Shiung Wu e a sua contribuição à Física [The trajectory of Chien Shiung Wu and her contributions to Physics]. Caderno Brasileiro de Ensino de Física, 36(1), 135-157. https://doi. org/10.5007/2175-7941.2019v36n1p135

Maia Filho, A. M., \& Silva, I. L. (2019b). O experimento WS de 1950 e as suas implicações para a segunda revolução da mecânica quântica [The WS experiment of 1950 and its implications for the second revolution of quantum mechanics]. Revista Brasileira de Ensino de Física, 41(2), e20180182. https://doi.org/10.1590/1806-9126-RBEF-2018-0182

Marchand, G. C., \& Taasoobshirazi, G. (2013). Stereotype Threat and Women's Performance in Physics. International Journal of Science Education, 35(18), 3050-3061. https://doi.org/10.1080/09500693.2012.683461

Marin, Y. A. O. (2019). Problematizando el discurso biológico sobre el cuerpo y género, y su influencia en las prácticas de enseñanza de la biología [Problematizing the Biological Discourse about the Body and Gender, and its Influence on the Teaching Practices of Biology]. Revista Estudos Feministas, 27(3), 1-10. https://doi.org/10.1590/1806-95842019V27N356283

Marshman, E. M., Kalender, Z. Y., Nokes-Malach, T., Schunn, C., \& Singh, C. (2018). Female students with A's have similar physics self-efficacy as male students with C's in introductory courses: A cause for alarm? Physical Review Physics Education Research, 14(2), 020123. https://doi.org/10.1103/PhysRevPhysEducRes.14.020123 
Martínez, A. J. G., Pitts, W., Robles, S. L. R. de, Brkich, K. L. M., Bustos, B. F., \& Claeys, L. (2019). Discerning contextual complexities in STEM career pathways: insights from successful Latinas. Cultural Studies of Science Education, 14(4), 1079-1103. https://doi. org/10.1007/s11422-018-9900-2

McCormick, M., Barthelemy, R. S., \& Henderson, C. (2014). Women's persistence into graduate astronomy programs: the roles of support, interest, and capital. Journal of Women and Minorities in Science and Engineering, 20(4), 317-340. https://doi. org/10.1615/JWomenMinorScienEng.2014009829

Minella, L. S. (2017). No Trono da Ciência I: mulheres no Nobel da fisiologia ou medicina (1947-1988) [In the realm of science I: women Nobel Prize in physiology or medicine (1947-1988)]. Cadernos de Pesquisa, 47(163), 70-93. https://doi. org/10.1590/198053143817

Namatende-Sakwa, L. (2019). Networked texts: Discourse, power and gender neutrality in Ugandan physics textbooks. Gender and Education, 31(3), 362-376. https://doi.org/1 0.1080/09540253.2018.1543858

Nehmeh, G., \& Kelly, A. M. (2018). Women physicists and sociocognitive considerations in career choice and persistence. Journal of Women and Minorities in Science and Engineering, 24(2), 95-119. https://doi.org/0.1615/JWomenMinorScienEng.2017019867

Nissen, J. M., \& Shemwell, J. T. (2016). Gender, experience, and self-efficacy in introductory physics. Physical Review Physics Education Research, 12(2), 020105. https:// doi.org/10.1103/PhysRevPhysEducRes.12.020105

Olaniyan, A. O., \& Govender, N. (2018). Effectiveness of polya problem-solving and target-task collaborative learning approaches in electricity amongst high school physics students. Journal of Baltic Science Education, 17(5), 765-777.

Patrão, M. (2015). Uma pequena biografia de Emmy Noether. E-Boletim Da Física, 4(3), $1-3$.

Pereira, Z. M., \& Monteiro, S. (2015). Gênero e Sexualidade no Ensino de Ciências No Brasil: Análise Da Produção Científica Recente [Gender and sexuality in science education in Brazil: Analysis of scientific production]. Contexto \& Educação, 30(95), 117-146. https://doi.org/10.21527/2179-1309.2015.95.117-146

Menezes, D. P. , Buss, K., A. Silvano, C., Nattrodt D’Avila, B., \& Anteneodo, C. (2018). A física da UFSC em números: Evasão e gênero [Physics Courses of the Federal University of Santa Catarina: Evasion and gender]. Caderno Brasileiro de Ensino de Física, 35(1), 324-336. https://doi.org/10.5007/2175-7941.2018v35n1p324

Pettersson, H. (2018). Multiple masculinities and gendered research personas: Between experiments, career choice and family. International Journal of Gender, Science and Technology, 10(1), 108-129. 
Potvin, G., \& Hazari, Z. (2016). Student evaluations of physics teachers: on the stability and persistence of gender bias. Physical Review Physics Education Research, 12(2), 020107. https://doi.org/10.1103/PhysRevPhysEducRes.12.020107

Pyenson, L. (1985). Cultural imperialism and exact sciences, German Expansion Overseas 1900-1930. Peter Lang.

Ramos, R. C., \& Tedeschi, S. P. (2015). A participação das mulheres na produção científica da UNESP, Campus de Rio Claro [The participation of women in the scientific production of UNESP, Campus of Rio Claro]. Caderno Espaço Feminino, 28(1), 140-151.

Reichenbach, C. Von, \& Dragowski, A. (2017). Trayectorias internacionales y proyectos locales: Análisis de una disputa en la institucionalización de la física en Argentina (19091910). Revista Brasileira de História Da Ciência, 10(2), 186-200.

Reznik, G., Massarani, L. M., Ramalho, M., Malcher, M. A., Amorim, L., \& Castelfranchi, Y. (2017). Como adolescentes apreendem a ciência e a profissão de cientista? [ How Teenagers Apprehend Science and the Scientist Profession?]. Revista Estudos Feministas, 25(2), 829-855. https://doi.org/10.1590/1806-9584.2017v25n2p829

Rodriguez, I., Potvin, G., \& Kramer, L. H. (2016). How gender and reformed introductory physics impacts student success in advanced physics courses and continuation in the physics major. Physical Review Physics Education Research, 12(2), 020118. https://doi. org/10.1103/PhysRevPhysEducRes.12.020118

Rosa, K., \& Mensah, F. M. (2016). Educational pathways of Black women physicists: Stories of experiencing and overcoming obstacles in life. Physical Review Physics Education Research, 12(2), 020113. https://doi.org/10.1103/PhysRevPhysEducRes.12.020113

Rosa, K., \& Silva, M. R. G. da. (2015). Feminismos e Ensino de Ciências: Análise de imagens de livros didáticos de Física [Feminisms and Science Teaching: Analysis of Physics textbook images]. Revista Gênero, 16(1), 83-104. https://doi.org/10.22409/ rg.v16i1

Ryan, L. M. (2012). “You must be very intelligent...?”: Gender and science subject uptake. International Journal of Gender, Science and Technology, 4(2), 167-190.

Sahin, M. (2014). The relationship between pre-service teachers' physics anxiety and demographic variables. Journal of Baltic Science Education, 13(2), 201-215.

Saitovich, E. B., Funchal, R. Z., Barbosa, M. C., Pinho, S. T. R. de, \& Santana, A. E. de. (2015). Mulheres na Física: Casos históricos, panoramas e perspectivas [Women in Physics: Historical cases, panoramas and perspectives]. Editora Livraria da Física.

Sannino, A., \& Vainio, J. (2015). Gendered hegemony and its contradictions among Finnish university physicists. Gender and Education, 27(5), 505-522. https://doi.org/10. 1080/09540253.2015.1045455 
Santos, V. M. dos. (2016). Uma "perspectiva parcial” sobre ser mulher, cientista e nordestina no Brasil [A "partial perspective" about being a woman, scientist and northeastern in Brazil]. Revista Estudos Feministas, 24(3), 801-824. https://doi. org/10.1590/1806-9584-2016v24n3p801

Sax, L. J., Lehman, K. J., Barthelemy, R., \& Lim, G. (2016). Women in physics: A comparison to science, technology, engineering, and math education over four decades. Physical Review Physics Education Research, 12(2), 020108. https://doi.org/10.1103/ PhysRevPhysEducRes.12.020108

Schiebinger, L. (1987). The history and philosophy of women in science: A review essay. Signs, 12(2), 305-332.

Schiebinger, L. (1999). Has feminism changed science? Harvard University Press.

Schiebinger, L. (2007). Getting more women into science: knowledge issues. Harvard Journal of Law \& Gender, 30, 365-378.

Scott, J. (1986). Gender: A useful category of historical analysis. The American Historical Review, 91(5), 1053-1075.

Sheldrake, R., Mujtaba, T., \& Reiss, M. J. (2017). Students' Changing Attitudes and Aspirations Towards Physics During Secondary School. Research in Science Education, 49, 1-26. https://doi.org/10.1007/s11165-017-9676-5

Silva, F. F. da, \& Ribeiro, P. R. C. (2014). Trajetórias de mulheres na ciência: "ser cientista" e "ser mulher" [Paths of women in science: "being a scientist" and "being a woman”]. Ciência \& Educação (Bauru), 20(2), 449-466. https://doi.org/10.1590/151673132014000200012

Sime, R. L. (2013). Marietta Blau: Pioneer of photographic nuclear emulsions and particle physics. Physics in Perspective, 15(1), 3-32. https://doi.org/10.1007/s00016-012-0097-6

Sinnes, A., \& Løken, M. (2014). Gendered education in a gendered world: Looking beyond cosmetic solutions to the gender gap in science. Cultural Studies of Science Education, 9(2), 343-364. https://doi.org/10.1007/s11422-012-9433-z

Souza, G. D. S., \& Silva, B. V. C. (2016). Um estudo exploratório sobre a concepção do cientista e do seu local de trabalho por estudantes de física [An exploratory study about the design of scientist and his workplace by students of physics]. Ciência Em Tela, 9(2), $1-11$.

Talves, K. (2016). Discursive self-positioning strategies of Estonian female scientists in terms of academic career and excellence. Women's Studies International Forum, 54, 157 166. https://doi.org/10.1016/j.wsif.2015.06.007

Teixeira, A. B. M., \& Freitas, M. A. (2015). Aspectos Acadêmicos e Profissionais sobre Mulheres Cientistas na Física e na Educação Física [ Academic and professional features about scientist women on physics and physical education]. Revista Ártemis, 20(2), 5765. https://doi.org/10.15668/1807-8214/artemis.v20n2p57-65 
Toma, R. B., \& Villagrá, J. Á. M. (2019). Preferencia por contenidos científicos de física o de biología en Educación Primaria: un análisis clúster [Preference for physics or biology scientific content in Elementary Education: a cluster analysis]. Revista Eureka Sobre Enseñanza y Divulgación de Las Ciencias, 16(1), 1104. https://doi.org/10.25267/ Rev_Eureka_ensen_divulg_cienc.2019.v16.i1.1104

Traxler, A., \& Blue, J. (2020). Disability in Physics: Learning from Binary Mistakes. In Physics Education and Gender: identity as an analytic lens (pp. 129-152). https://doi. org/10.1007/978-3-030-41933-2_8

Traxler, A., Cid, X. C., Blue, J., \& Barthelemy, R. (2016). Enriching gender in physics education research: A binary past and a complex future. Physical Review Physics Education Research, 12(2), 1-15. https://doi.org/10.1103/PhysRevPhysEducRes.12.020114

UNESCO. (2017). Women in Science: Fact sheet no 43. http://uis.unesco.org/sites/ default/files/documents/fs43-women-in-science-2017-en.pdf

Universidade de Brasilia. (2020). Meninas na Ciência. https://www.meninasnacienciaunb. com.br/

Universidade de Campinas. (2020). Meninas SuperCientistas. https://www.ime.unicamp. br/meninassupercientistas/

Universidade Federal do Rio de Janeiro. (2020). Meninas com Ciência. http://www. museunacional.ufrj.br/dgp/extensao_meninascomciencia.html

Universidade Federal do Rio Grande do Sul. (2020). Meninas na Ciência. https://www. ufrgs.br/meninasnaciencia/

Wang, J., Hazari, Z., Cass, C., \& Lock, R. (2018). Episodic memories and the longitudinal impact of high school physics on female students' physics identity. International Journal of Science Education, 40(13), 1543-1566. https://doi.org/10.1080/09500693.2018.14865 22

Whitten, B. L. (2012). (Baby) steps toward feminist physics. Journal of Women and Minorities in Science and Engineering, 18(2), 115-134. https://doi.org/10.1615/ JWomenMinorScienEng.2012003648

Worthen, M. G. F. (2016). Hetero-cis-normativity and the gendering of transphobia. International Journal of Transgenderism, 17(1), 31-57. https://doi.org/10.1080/1553273 9.2016.1149538

Zander, L., Wolter, I., Latsch, M., \& Hannover, B. (2014). Qualified for teaching physics? How prospective teachers perceive teachers with a migration background - and how it's really about "him" or "her." International Journal of Gender, Science and Technology, 7(2), 255-279. 


\section{Carolina de Barros Vidor}

https://orcid.org/0000-0001-7951-7034 Federal University of Rio Grande do Sul Institute of Physics

Graduate Program in Physics Education Porto Alegre, Rio Grande do Sul, Brazil carolina.vidor@gmail.com

\section{Anna Danielsson}

https://orcid.org/0000-0002-3407-9007

Uppsala University Department of Education Uppsala, Sweden anna.danielsson@edu.uu.se

\section{Flavia Rezende}

https://orcid.org/0000-0002-5739-7905 Federal University of Rio Grande do Sul Institute of Physics Graduate Program in Physics Education Porto Alegre, Rio Grande do Sul, Brazil flaviarezende@uol.com.br

\section{Fernanda Ostermann}

https://orcid.org/0000-0002-0594-2174 Federal University of Rio Grande do Sul Institute of Physics

Graduate Program in Physics Education Porto Alegre, Rio Grande do Sul, Brazil fernanda.ostermann@ufrgs.br

Submitted on 22nd April 2020 Accepted on 18th August 2020 Published on 05th November 2020 